Do journalists' opinions affect news selection in a low-key conflict?

Newspaper coverage of the discussion of smoking bans in Switzerland

Peter J. Schulz, Uwe Hartung and Maddalena Fiordelli

Revised manuscript accepted January 20, 2012 by Journalism \& Mass Communication Quarterly, with final requirements for minor changes addressed

January 27, 2012

Università della Svizzera italiana, Institute of Communication and Health

Via Giuseppi Buffi 13, 6904 Lugano, Switzerland

Phone +41 58 666-4724 (Schulz) -4483 (Hartung)

Fax +4158 666-4647

peter.schulz@usi.ch

uwe.hartung@usi.ch

maddalena.fiordelli@usi.ch

Key words: Instrumental actualization, Synchronization of news and opinion, Conflict coverage,

Argumentation, Content analysis, Smoke-free legislation 


\title{
Do journalists' opinions affect news selection in a low-key conflict? \\ Newspaper coverage of the discussion of smoking bans in Switzerland
}

Peter J. Schulz, Uwe Hartung and Maddalena Fiordelli

\begin{abstract}
This study applies the theory of instrumental actualization to Swiss newspaper coverage of smoking bans in public places, using quantitative content analysis. The theory holds that journalists' opinions affect news selection; it is studied here for the weighting and evaluation of arguments in news stories. The study finds that the editorial stance of newspapers was related to the weighting of argumentative fields and the frequency of contradiction different standpoints. Therefore elements of both a dialectical (papers of different stance explicitly contradicting one another) and a rhetorical (papers of different stance speaking of different matters) model of discourse was found.
\end{abstract}

\section{Author information}

Professor Peter J. Schulz (Ph.D., Katholische Universität Eichstätt-Ingolstadt, Germany) is the director of the Institute of Communication and Health at the Università della Svizzera italiana, Lugano. Uwe Hartung (Ph.D., Johannes Gutenberg University, Mainz, Germany) and Maddalena Fiordelli (Ph.D., Università della Svizzera italiana) are senior researchers there. The research reported was funded by Tabakpräventionsfond, Switzerland. 
One of the most cherished maxims of journalists' self-image is C. P. Scott's formula "Comment is free, but facts are sacred," made 90 years ago in the Guardian and called "the ultimate statement of values for a free press" some 80 years later. ${ }^{1}$ The sacredness of facts primarily refers to the truthful reporting of events, but the formulation suggests more: that comments and facts are different spheres and that facts come first, are established with care and sincerity and remain unaffected by the opinions and interests of the person who reports and selects the facts. The theory of instrumental actualization, developed by Hans Mathias Kepplinger, challenges this view, claiming that journalists' opinions affect the selection of facts in news reporting. This article applies this theory to the reporting of arguments in the news and tests it for the case of Swiss newspaper coverage of smoke-free legislation.

The theory of instrumental actualization ${ }^{2}$ explains the selection of news by the mass media in conflicts. ${ }^{3}$ The theory posits that journalists hold opinions towards the issues of the day, and that the staff in a newsroom, at least in media with a discernable political profile or leaning, also holds collective opinions on these issues. When an issue is discussed broadly, there is a multitude of news stories available that are instrumentally linked with conflict positions, that is to say: they help one or the other side to defend their stand on the issue. In a conflict about tobacco control measures, for instance, a news item about lay-offs in the tobacco industry is something that will be perceived by most as an item instrumental to the opponents of the measures because unemployment is an undesirable state to most. On the other hand, an item about the continuingly high rates of tobaccorelated deaths will be seen as helping the camp favorable to control measures. News items on tobacco-related deaths are therefore instrumental to bolstering the opinion that control measures are a good thing.

The crucial claim of instrumental actualization is that journalists (individuals or groups) will primarily select those news stories for publication that support their own view on an issue, respectively those that damage or challenge the other side. They do not necessarily do this 
consciously. As a consequence of this selection pattern, media outlets with different views on an issue will present different facts as relevant in their news sections, or in a wider perspective: outlets with different political leanings will depict different realities. The theory thus challenges the ideal of the separation of fact and opinion. ${ }^{4}$ The adaption of news selection to an issue position or a general political point of view is called synchronization. ${ }^{5}$ That the theory identifies one influence on news selection does not imply that other factors ${ }^{6}$ are denied.

The theory does not specify the origin of journalists' opinions. Opinions can refer to individual views, to institutional views of the news organization a journalist works for, to professional views more or less shared by their colleagues, and finally to cultural views more or less prevalent in the country or culture a journalist lives in. The latter two origins would result in consonant news selection, that is to say: they could explain why news are similar across outlets in a given country. Instrumental actualization, however, has been more concerned with the ways news selection differs between outlets, which can only be caused by personal or institutional opinions, not by professional or cultural ones.

The theory of instrumental actualization in its original formulation focused on the selection of events for news reporting. Instead of events (better: news stories about events) we analyze arguments reported in the news. We define an argument as a statement relating a standpoint supported by evidence. ${ }^{7}$ A statement relating a standpoint without support by evidence is called an opinion. Argumentation is a prominent feature of news in a conflict. Many news stories focus on statements made in press releases, press conferences or interviews, and many contain arguments. In fact, the instrumentality of events as conceived in classic instrumental actualization studies is based on their potential to make an argument of them. Therefore our focus on arguments is not so different from the earlier studies that focused on events.

The degree to which instrumental actualization is at work in the selection of arguments in news coverage has implications for the style of discourse in a society. If arguments are selected 
according to their instrumentality for defending an issue position, then media outlets with different issue positions will report different arguments. Supposing recipients form their opinions on the basis of the arguments known to them in part from the media they use, different issue positions among the population will be based on the news media giving different emphasis to arguments. The two camps in a conflict would then, in a sense, talk past one another, which could be called a rhetorical style of discourse. Its major quality is the different weighting of subject matter. If, on the other hand, the presentation of arguments in the news is independent of journalists' issue positions, the arguments presented will be more similar across different media outlets, but their relevance and validity will be assessed differently (or else there would not be conflict). Recipients will then base their opinions on the different evaluation of similar arguments rather than similar evaluations of different arguments as in the former case. The latter can be called a dialectical style of discourse, following the model of a dialogue, while the rhetorical style corresponds to a model of two (or more) monologues. ${ }^{8}$ A dialectic style is based on different evaluation. Real discourse can, of course, contain elements of both models.

To cover both the weighting of arguments and their evaluation, the possibility of contradicted arguments has to be taken into account. An argument advocating a standpoint might be adduced by a source only to contradict it. An example is: "In Montgomery County, MD, local politicians were seriously discussing to ban smoking on people's own patios and garden when it bothers neighbors - a plan abandoned in the meantime. ${ }^{\prime 9}$ To account for this possibility we distinguish between the original standpoint advocated by an argument and the final standpoint. If an argument is adduced in an affirming way or just neutrally (i.e. without any evaluation) the original and the final standpoint are identical. If however an argument is adduced and then contradicted by the same speaker (source), the final standpoint is the opposite of the original one. In the cited example, the original standpoint is for the ban (will reduce molestation, harassment of non-smokers, the final is against ("seriously", plan abandoned). The logic of this classification can be summarized in this formula 
Original standpoint $X$ Evaluation $(+1 /-1)=$ Final standpoint

This study tests whether either a rhetorical, monologue-type model of discourse, or its opposite, a dialogue model, describes Swiss newspapers' coverage of the conflict about the introduction of a smoking ban in public places. This is done in four steps. First, we assess the presence of synchronization, which suggests instrumental actualization is at work and discourse has a rhetorical quality. We hypothesize accordingly:

H1: The more positive the editorial stance towards a smoking ban is in a newspaper, the more favorable to the ban will the stance of the news section be.

For assessing the degree to which different weighting of arguments is an element in newspaper coverage, the original standpoint of arguments is an obvious starting point. Disregarding the evaluation of arguments for the second step of analysis altogether, we hypothesize:

H2: The more supportive of the ban the editorial stance of a paper is, the more weight will arguments with an original standpoint in favor of the ban get in the news stories.

We consider this a test of instrumental actualization, proxying journalists' issue position (the actual independent variable) by editorial stance.

H2 conceives of instrumentality as a binary variable. But different arguments advocating the same standpoint can have different persuasive strengths, and thus different degrees of instrumentality. One approach to this is grouping arguments into argumentative fields according to the subject matter adduced, which might be health, or financial matters, or judicial matters, etc. If the instrumentality of these fields can be determined, their weighting in the newspapers can be correlated with editorial stance and thus related to the overall research question. Defining the subject area on which an issue is discussed in the media, and probably decided, has come to be labeled issue framing for the last two decades. ${ }^{10}$ The analysis therefore deals with the weighting of 
frames, but we will use our terminology to make clear it grows out of the study of arguments. We hypothesize:

H3: The more supportive of the ban the editorial stance of a paper is, the more weight in the news stories will the argumentative fields get that are instrumental to an issue position for the ban.

Depending on the classification of the instrumentality of the argumentative fields, sub-hypotheses on this will be formulated below.

The degree to which $\mathbf{H} \mathbf{1}$ to $\mathbf{H} \mathbf{3}$ will be supported will indicate the existence of instrumental actualization and a rhetorical, monologue type of discourse. The final analysis addresses the other side, a dialectical type of discourse. It holds:

H4: The more supportive of the ban the editorial stance of a paper is, the less often arguments advocating an original standpoint for the ban (H4a), and the more often arguments advocating an original standpoint against will be contradicted in the news stories (H4b).

Support for these two hypotheses would challenge the concept of instrumental actualization and the rhetorical model of discourse.

\section{Method}

Our study deals with the coverage of smoke-free legislation in Swiss newspapers. At the time of the study, such legislation was seriously discussed in several of the country's cantons, but no cantonal or nation-wide regulations to ban smoking from public places were in effect. Decision came fastest in Ticino, and the period of study was defined to cover the Ticino discussion from the time it 
began to be broadly covered by the newspapers there (October 2004) until a month after the ban was put into effect there (May 2007). The analysis was not restricted to the Ticino discussion but included smoking bans everywhere.

The selection of newspapers aimed at including all three major lingual regions of the country, at including different types of papers (if existent) and at optimizing output. Therefore, after including two German-language quality papers and the dominating tabloid, and also a weekly paper for each of the language regions, the biggest regional dailies (in terms of copies sold) were included. This procedure covers almost all important newspapers of the French- and Italian-speaking parts of the countries, but neglects papers from the central and eastern sections of the German-speaking part, where newspapers happen to be smaller. As we are not making claims for the Swiss newspapers in general, the issue of whether the sample is statistically representative is of no concern here. Included were seven Swiss German, six Swiss French and four Swiss Italian newspapers: Neue Zürcher Zeitung, Tagesanzeiger, Berner Zeitung, Basler Zeitung, MittellandZeitungen, Blick and Sonntagsblick; Vingtquatre Heures, Tribune de Genève, Le Nouvelliste, Le Temps, Matin and Matin Dimanche; Corriere del Ticino, Giornale del populo, La regione, and II caffè. Articles were retrieved from the Swissdox database, using the German, French and Italian equivalents of "smoking ban" as search terms.

Coding was done on both the article and the statement level. Five article-level variables were measured (newspaper; type of author; publication date; section; type of article such as news report, opinion piece, interview etc.), of which only the newspaper and the type of article were employed for the present analysis. Only evaluative statements were considered in statement-level coding. They were defined as statements from which somebody's stand on the issue of smoking bans could be inferred. Evaluative statements could be arguments (evidence provided) or opinions (no evidence). Five variables were measured on statement level (source; political level for which a ban is discussed such as a particular canton, city, or country; institution for which a ban is discussed 
such as restaurants, hotels, or public transportation; substance of argument; final standpoint), of which three are used in this analysis. The first was the substantive content of the argument, consisting of 20 categories for arguments in favor of the ban and 13 categories for arguments against. Examples of argument categories are "Smoking ban will reduce molestation, harassment of non-smokers by smoke," "Reduction of passive smoking of people who work in bars, restaurants, etc.," and "Financial losses." The codebook clearly separated arguments advocating a standpoint for the ban from those advocating the opposite. There were two categories for statements that pronounce a standpoint, but give no evidence (= opinions). All categories were defined and many were illustrated by an example.

The second variable used was the final standpoint advocated in the argument, which was coded in just two categories, for and against the ban. In coding this, contradictions of arguments had to be considered. Thirdly the source (speaker) of an argument was used, but only in a marginal analysis.

For reliability testing, three coders independently coded five articles. Reliability was measured by Cohen's kappa (corresponding to Holsti's agreement formula, corrected for chance agreement). ${ }^{11}$ Coefficients were calculated pair-wise; their average values were .70 for source, .63 for argument, and .57 for final standpoint. The latter coefficient just falls short of the threshold for substantial agreement $(.61),{ }^{12}$ but it has to be taken into account that our analysis comprises material in three different languages and employed coders of different native languages, which can be expected to create special reliability problems.

Measurement has the statement as unit of analysis. For the calculations reported in this article, however, statement-level measures were aggregated on the newspaper level. The newspaper is thus the unit of analysis in what follows, and the variables on the newspaper level (all expressed as percentages) were determined by aggregating statement-level measures. 
Editorial stance of a newspaper (independent variable in $\mathbf{H 1 - H 4 )}$ was operationally defined as the share of statements (arguments plus opinions) with a final standpoint for the ban among all statements made in opinion pieces (irrespective of the source). An alternative indicator was computed: share of evaluative statements with a final standpoint for the ban among all statements made by journalists (irrespective of newspaper section). Both indicators were highly correlated (Kendall's tau_ $b=.54, \mathrm{~N}=16, \mathrm{p}<.01$ ), and only the former was used as it is more clearly different from the dependent variable of $\mathbf{H} \mathbf{1}$.

Stance of news section (dependent variable in $\mathbf{H} \mathbf{1}$ ) was defined as the share of statements (arguments plus opinions) with a final standpoint for the ban among all statements made in factual articles (news reports, etc.).

Weight of original standpoints in favor of the ban (dependent variable in $\mathbf{H 2}$ ) was computed as the share of arguments with this original standpoint among all arguments, with opinions completely excluded. The standpoints for and against the ban were determined by recoding the argument variable, which already was differentiated into "for" and "against" at measurement.

Argumentative field was also determined by recoding the argument variable, irrespective of which standpoint was advocated, and again excluding the opinions. Arguments were grouped into six argumentative fields. Health arguments were holding that a ban would reduce passive smoking, especially for employees in the hospitality branch or for children and that the health of smokers would also benefit from reduced use of tobacco. There were many unspecified references to the improvement of public health. The only health-related argument against the ban was that there could be other ways than a ban to reduce passive smoking.

The social relations field includes arguments that the ban would reduce harassment of nonsmokers, that relations between non-smokers and smokers would improve, and that the ban was justified because non-smokers were a majority or because the majority wanted it. Arguments 
against the ban in this field were that the ban would increase harassment, worsen social relations between smokers and non-smokers or stigmatize smokers. The field of experience/compliance arguments put forth that earlier or other regulations of smoking in public places worked or did not work, that therefore new regulations were necessary or not, and that a ban would or would not be abided by.

The field of legal protection and freedom contains just one argument on either side: that non-smokers deserve the protection of the law and that the smokers' freedom should not be infringed. The field of economic arguments includes the mentioning of all kinds of financial consequences of smoking bans, both benefits and damages. They almost all concern the hospitality branch, i.e. restaurants, bars, hotels, etc., although the consequences for other branches were coded as well. And finally, the statements grouped into the level of/time for decision field made their point by mentioning local, cantonal or federal competences for smoke-free legislation, and whether one's own canton should or could play an avant-garde role or be a role model in the fight against tobacco.

To determine the instrumentality of these fields, a yardstick is necessary that demonstrates how similarly aspects are evaluated. In the classic German studies, four nationally distributed quality papers of pronouncedly different political leanings were used. ${ }^{13}$ In absence of such a standard for Swiss newspapers, we take the complete number of arguments in the sample (all types of articles, all sources) as a yardstick. Details of the way the instrumentality of argumentative fields was determined is described below. Their weight (dependent variable in $\mathbf{H 3}$ ) is determined as the share of all arguments belonging to a field among all arguments in the news section, again excluding the opinions.

Frequency of contradictions (dependent variable in $\mathbf{H 4}$ ) was determined by comparing the original (as described for $\mathbf{H} \mathbf{2}$ above) and final standpoint as coded. If they differed, an argument was contradicted. Frequency is expressed as the share of contradicted among all arguments, computed 
separately for the two original standpoints for and against the smoking ban. All variables in the analysis were aggregated for newspaper and expressed as a percentage. All analyses are correlations across the number of available newspapers ( $n=17$ or less), using Kendall's tau_b because of the low number of cases and the proximity of values. Given the small $n$, correlations have to be rather strong to become significant. The method applied is therefore rather conservative. In some cases the correlations are illustrated by scatter plots, which also show linear trends for illustration.

\section{Results}

Overview. In the 32-months period under study, we found 3186 articles in the 17 newspapers. These articles contained 20234 evaluative statements on smoking bans, of which 12042 or $59.5 \%$ were arguments and the remaining 8192 (40.5\%) were opinions. Newspaper coverage was overwhelmingly supportive of smoking bans. Taking all statements together, almost three in four (74\%) voiced a final standpoint for the ban, while only $26 \%$ were against it. The pro-ban bias was observed in all 17 newspapers under study. Shares of final standpoints in favor of bans ranged from $67 \%$ in the daily tabloid Blick and its Sunday edition Sonntagsblick to $87 \%$ in the Ticino weekend paper I/ caffè. The conflict about banning cigarettes and other tobacco products from public places was therefore one-sided as far as newspapers were concerned. This means we only compare papers that, on balance, were supportive with those that were very supportive.

Overall, $69 \%$ of the articles in this study are news items and reports, $11 \%$ are journalistic opinion pieces, $15 \%$ letters to the editor, and $3 \%$ interviews. We only consider the former two categories in the comparison of editorial stance with the selection of arguments reported in the news sections.

Among the 7771 arguments in the news sections, $66 \%$ originally advocated a standpoint for the ban and the remaining $34 \%$ were originally against. Among the former only $4 \%$ were 
contradicted. Of the arguments originally advocating a standpoint against the ban, a considerable share of $24 \%$ was contradicted.

Argumentative fields and their instrumentality. The most frequently addressed argumentative field was health, and the health benefits of a smoking ban for non-smokers are usually the major motivation for banning smoking from public places. There were 3936 arguments relating to health in the newspapers studied (all sections), comprising a share of $33 \%$ of all arguments. There is consensus among the papers that health-related arguments speak for a ban. Almost four in five arguments advocated this final standpoint (78\%), with a high consonance across papers, as evidenced by the comparatively low standard deviation shown in Table 1. Health is thus an argumentative field instrumental to the position that supports the ban, and we expect that it will be given the more weight in the news sections of papers the more favorable to the ban the editorial stance is $(\mathbf{H 3 a})$.

Much the same can be said of the fields of social relations/majority rules and experience/compliance arguments. Social relations arguments comprised $15 \%$ of all arguments, and experience/compliance arguments $9 \%$. The arguments in both fields were overwhelmingly for the ban (final standpoint) and the standard deviation comparable to the low value for health arguments. We therefore expect both the fields of social relations/majority rules arguments and experience/compliance arguments to be instrumental for a position favoring the ban. The more supportive of the ban the editorial stance of a paper is, the more weight in the news stories will both these argumentative fields get ( $\mathbf{H} \mathbf{3} \mathbf{b}$ and $\mathbf{H} \mathbf{3} \mathbf{C})$.

Two other argumentative fields do not show a similar consensus in evaluation. They are legal protection and freedom arguments, as well as economic arguments. Only slightly above $50 \%$ of the arguments in these two fields support the ban (final standpoint), indicating that arguments here were almost used as often against as for the ban. The average share of arguments with a final standpoint for the ban across papers was $49 \%$ for the legal arguments and $58 \%$ for the economic 
arguments. Individual papers distributed rather widely around that, as the relatively high standard deviations in Table 1 show. These two argumentative fields therefore provided material for both sides. As there was no argumentative field that could be clearly determined as instrumental to the position against the ban, we expect that the more supportive of the ban the editorial stance of a paper is, the less weight in the news stories will the argumentative fields of legal and economic arguments get (H3d and $\mathbf{H} \mathbf{3} \mathbf{e})$. The remaining field, level of/time for decision arguments is not further considered here because it cannot be classified as instrumental to either side.

\section{Insert Table 1 about here}

Hypothesis testing. As expected, the editorial stance was favorable to the ban in most papers, as were the final standpoints advocated in arguments and opinions cited in news stories. Speaking in terms of illustration, the fact that most papers are placed in the upper right-hand quadrant in Figure 1 (pertaining to $\mathbf{H} \mathbf{1}$ ) supports the notion of synchronization of news and opinions and thus the theory of instrumental actualization. Two papers show a more balanced editorial position on smoking bans, the leading quality newspaper of Switzerland, Neue Zürcher Zeitung, and the dominating tabloid, Blick. In spite of their not favoring the ban in their own opinion pieces, these two papers still published many more statements advocating a final viewpoint in favor of smoking bans.

Across all 17 papers, editorial stance significantly correlates with the stance of the news sections (see Table 2). $\mathbf{H} \mathbf{1}$ is supported. Figure 1 illustrates the correlation.

Insert Figure 1 about here

Weighting of original standpoints in the arguments reported in the news was independent of editorial stance (Table 2). $\mathbf{H 2}$ cannot be supported. 
H3a to H3e dealt with weighting of argumentative fields. We expected the more favorable the editorial stance to smoke-free legislation was, the more weight should be given to the fields of health, social relations/majority rules and experience/compliance arguments (H3a to H3C), and the less weight to economic and legal arguments ( $\mathbf{H} \mathbf{3 d}$ and $\mathbf{H 3 e})$.

Only H3a and $\mathbf{H 3 e}$ were supported (Table 2). Figures 2 and 3 illustrate the corresponding correlations between editorial stance and the weighting of the argumentative fields of health and legal/freedom arguments and their different directions.

Insert Figures 2 and 3 about here

$\mathbf{H} \mathbf{2 b}$ and $\mathbf{H} \mathbf{2 c}$ were not supported. The correlations, expected to be positive, turned out to be negative (if a marginal significance level of $p<.10$ is accepted; Table 2). Similarly, $\mathbf{H} \mathbf{2} \mathbf{d}$ was not supported; the correlation, expected to be negative, turned out to be positive, although it just fails to reach even marginal significance levels.

The evidence for different weighting of argumentative fields as a consequence of different editorial stances among papers is thus mixed. The more supportive papers were in their opinion pieces, the more did they publish health-related arguments in their news sections, and the less did they turn to legal protection/freedom arguments. Both these relationships were expected. But the weight put on the field of health also seemed to occur at the expense of two other argumentative fields also thought to be instrumental for the position favoring the ban, social relations/majority rules and experience/compliance arguments. And papers more supportive of the ban also did not shun economic arguments as expected.

Insert Table 2 about here

The contradictory results can be explained in part by the fact that the five dependent variables above are not independent of each other. They are percentages indicating the share that a 
particular argumentative field holds among all arguments. That is to say: any of the five variables can increase only at the expense of the others. This condition and other findings suggest that unexplained factors complement the effect of instrumental actualization on the weighting of argumentative fields, which, however, is also present, as can be seen in the results on health and legal arguments.

Finally, editorial stance was found not to be correlated with frequency of contradicting original standpoints for the ban, but it did correlate significantly with the frequency of contradicting original standpoints against the ban (Table 2). H4a thus was not supported, while H4b was confirmed. Figure 4 illustrates the latter.

Insert Figure 4 about here

The mixed results on the weighting of argumentative fields suggest examining the weighting of original standpoints ( $\mathbf{H 2}$ ) and the frequency of contradiction ( $\mathbf{H} \mathbf{4 a}$ and $\mathbf{H} \mathbf{4 b}$ ) within argumentative fields. Original standpoints were not found to be correlated with editorial stance for all arguments together, but they were within the field of legal protection/freedom arguments, but in the unexpected direction. Frequency of contradicting original standpoints for the ban was neither found to be correlated with editorial stance for all arguments together, but they were in the expected negative direction within the fields of legal protection/freedom, social relations/majority rules and (marginally significant) experience/compliance arguments. Frequency of contradicting original standpoints against the ban was found to be correlated with editorial stance for all arguments together, but this was only replicated for the field of economic arguments. Table 3 shows the results in detail.

Insert Table 3 about here 


\section{Discussion}

If the two models of discourse are plotted against one another, evidence is very mixed.

There are elements in the newspaper coverage of smoke-free legislation that support the notion of rhetorical, monologue-type of discourse and the related theory of instrumental actualization. These elements are the evidence of synchronization between opinion pieces and the news and the weighting of two argumentative fields, health and legal/freedom arguments. But there are also strong elements of a more dialectical model of discourse. These are the absence of evidence for weighting of original standpoints in line with editorial stance, and the frequency of contradicting original standpoints in line with editorial stance, found overall for negative standpoints, but within some argumentative fields for positive ones as well.

Several features can explain the coexistence of both models. One is that the conflict about smoke-free legislation was very one-sided among the newspapers studied here. There were no newspapers against the legislation, so comparisons could only consider different degrees of support. Also the Swiss population was overwhelmingly for a smoking ban. ${ }^{14}$ Moreover, this issue was only weakly linked with ideological positions, although in Ticino, the political opposition to the ban was the stronger the more to the right a party was situated. ${ }^{15}$

The situation, in other words, was not very apt to study a theory of news selection in conflict. If we take this into account, the support for instrumental actualization we found is stronger than it might appear at a first glance. That we find good evidence of synchronization is more surprising when we take into account that (a) the editorial stances were all on the same side of the conflict and (b) there was only small variance in the tendency of the news sections. Even under these unfavorable conditions did evidence of synchronization emerge. This suggests there is a reality behind the concept. The same can be argued for instrumental actualization with regard to the differing weighting patters of health (weighted up in papers with more positive editorial stance) and legal arguments (weighted down by these papers). 
The patterns found are not uniform across different argumentative fields (reading Table 3 again). Because of a clear weighting up of the issue in papers editorially favoring the ban and the absence of significant results on frequency of contradiction, health is the issue most clearly following a rhetorical model of discourse. Social relations/majority rules and experience/compliance arguments, on the other hand, were weighted down by papers strongly favoring the ban, against expectations. When the two fields were addressed, standpoints for the ban were not (as expected) reported more often by papers in favor, but they were contradicted less frequently. Given that contradiction to favorable standpoints does not occur often, the evidence gained from these two fields is mostly against a rhetorical and hardly for a dialectical model either. As to legal protection/freedom arguments, newspapers with a pronounced stance for the ban tended to shun this field, but when they addressed it, they put emphasis on the opposing standpoint. This would suggest that they also contradicted these arguments more often, but they did not. They did however contradict favorable standpoints less often. Again, this is difficult to interpret as either providing clear evidence for a rhetorical or a dialectical model. And finally, economic arguments were not weighted as expected, but newspapers editorially favorable to ban were inclined to contradict arguments that stated losses of revenue. This is the field most clearly supporting a dialectical model of discourse. This variety of results suggests looking more deeply into the interaction of argumentative field weighting, weighting of standpoints and frequency of contradiction in argumentative newspaper coverage. 


\section{Endnotes}

1 "Comment is Free, but Facts are Sacred, “ Guardian, November 29, 2002,

http://www.guardian.co.uk/commentisfree/2002/nov/29/1

${ }^{2}$ Hans Mathias Kepplinger, "Instrumentelle Aktualisierung," Publizistik 29 (1, 1984): 94-5; Hans Mathias

Kepplinger, with Hans-Bernd Brosius, Joachim Friedrich Staab and Günter Linke, „Instrumentelle

Aktualisierung. Grundlagen einer Theorie publizistischer Konflikte, "in Massenkommunikation. Theorien,

Methoden, Befunde, ed. Max Kaase and Winfried Schulz (Opladen: Westdeutscher Verlag, 1989, = special issue No. 30 of the Kölner Zeitschrift für Soziologie und Sozialpsychologie), 199-220; Hans Mathias Kepplinger, HansBernd Brosius, Joachim Friedrich Staab, "Opinion Formation in Mediated Conflicts and Crises: A Theory of Cognitive-Affective Media Effects," International Journal of Public Opinion Research 3 (2, 1991): 132-56; Hans Mathias Kepplinger, Hans-Bernd Brosius, Joachim Friedrich Staab, "Instrumental Actualization. A Theory of Mediated Conflicts," European Journal of Communication $6(3,1991)$ : 263-90; for a brief overview see Uwe Hartung, "Instrumental actualization," in The International Encyclopedia of Communication, Vol. V, ed. Wolfgang Donsbach (Malden, MA: Blackwell, 2008), 2295-7.

${ }^{3}$ See Gadi Wolfsfeld, Media and Political Conflict (Cambridge: Cambridge University Press, 1997); Simon Cottle, Mediatized Conflixt: Developments in Media and Conflict Studies (Maidenhead: Open University Press, 2006).

${ }^{4}$ Donald L. Shaw and Thomas C. Terry, "Separation of News and Comments," in The International Encyclopedia of Communication, Vol. X, ed. Wolfgang Donsbach (Malden, MA: Blackwell, 2008), 4576-8.

${ }^{5}$ Klaus Schönbach, Trennung von Nachricht und Meinung: Empirische Untersuchung eines journalistischen Qualitätskriteriums (Freiburg i.Br., München: Alber, 1977); Lutz Hagen, “Die opportunen Zeugen:

Konstruktionsmechanismen von Bias in der Zeitungsberichterstattung über die Volkszählungsdiskussion," Publizistik 37 (4, 1992): 444-60.

${ }^{6}$ Pamela J. Shoemaker, Gatekeeping (= Communication Concepts, Vol. 3; Newbury Park, CA.: Sage, 1991); Pamela J. Shoemaker and Stephen D. Reese, Mediating the Message: Theories of Influences on Mass Media Content ( $2^{\text {nd }}$ ed., New York, London: Longman, 1996); Stephen D. Reese, "Setting the Media's Agenda: A Power Balance Perspective," in Communication Yearbook, Vol. 14, ed. J. A. Anderson (Newbury Park: Sage, 1991), 309-56; Kevin Barnhurst, "News Ideologies in the Twentieth Century," in Diffusion of the News Paradigm, 1850-2000, ed. S. Høyer and H. Pöttker (Gothenburg: Nordicom, 2005); 239-62; Hans Mathias Kepplinger, "News Values," in The International Encyclopedia of Communication, Vol. VII, ed. Wolfgang Donsbach (Malden, MA: Blackwell, 2008), 3281-6.

${ }^{7}$ Frans H. van Eemeren and Rob Grootendorst, A Systematic Theory of Argumentation. The Pragma-dialectical Approach (Cambridge: Cambridge University Press, 2004); Stephen E. Toulmin, The Uses of Argument (Dordrecht: Kluwer Academic Publishers, 1958); Peter Schulz and Sara Rubinelli, "Healthy Arguments for Literacy in Health," in Technical Report of the American Association for Artificial Intelligence (AAAI): Stanford Spring Symposium on Argumentation for Consumers of Healthcare (2006), 86-95; Peter J. Schulz and Sara Rubinelli, "Arguing 'for' the Patient: Informed Consent and Strategic Maneuvering in Doctor-Patient Interaction," Argumentation 22 (3, 2008): 423-32.

${ }^{8}$ This relationship of instrumental actualization to rhetorical and dialectical styles of discourse was already described in the first publications on the theory, see note 2.

9 "Rauchverbot auf der eigenen Terrasse," Neue Zürcher Zeitung, August 13, 2005, 71.

${ }^{10}$ See e.g. Robert M. Entman, “Framing: Toward Clarification of a Fractured Paradigm," Journal of Communication 43 (autumn 1993): 51-8; Zhongdang Pan and Gerald M. Kosicki, "Framing Analysis: An Approach to News Discourse," Political Communication 10 (spring 1993): 55-75

${ }^{11}$ Jacob Cohen, "A Coefficient of Agreement for Nominal Scales," Educational and Psychological Measurement, 20 (1, 1960): 37- 46; Ole R. Holsti, Content Analysis for the Social Sciences and Humanities (Reading MA: Addison-Wesley, 1969).

12 J. R. Landis and G. G. Koch, "The Measurement of Observer Agreement for Categorical Data," Biometrics 33 $(1,1977)$ : 159-74; Steve Stemler 2001. "An Overview of Content Analysis," Practical Assessment, Research, and Evaluation 7 (17, 2001). Retrieved November 23, 2011 from http://PAREonline.net/getvn.asp?v=7\&n=17.

${ }^{13}$ Hans Mathias Kepplinger, Die aktuelle Berichterstattung des Hörfunks: Eine Inhaltsanalyse der Abendnachrichten und politischen Magazine (Freiburg, München: Alber, 1985); Kepplinger et al., “Instrumentelle Aktualisierung” (1989); Kepplinger et al., "Instrumental Actualization” (1991); Rainer Mathes, "Der publizistische Konflikt um das Moderationsverbot für Franz Alt. Eine empirische Studie zur öffentlichen 
Konfliktkommunikation, " Publizistik 32 (2, 1987): 166-79, Rainer Mathes, “Medienwirkung und Konfliktdynamik in der Auseinandersetzung um die Entlassung von General Kießling. Eine Fallstudie und ein Drei-Ebenen-Modell," in Massenkommunikation. Theorien, Methoden, Befunde, ed. Max Kaase and Winfried Schulz (Opladen: Westdeutscher Verlag, 1989, = special issue No. 30 of the Kölner Zeitschrift für Soziologie und Sozialpsychologie), 441-58; Stefan Dahlem and Rainer Mathes "Der Konflikt um die ,Mietenlüge":

Kommunikationsstrategien und Presseberichterstattung im Bundestagswahlkampf 1982/83," Politische Vierteljahresschrift 30 (4, 1989): 655-73.

${ }^{14}$ Theda Radtke, Roger Keller, Hans Krebs and Rainer Hornung, Passivrauchen in der Schweizer Bevölkerung 2008. Zusammenfassung des Passivrauchberichts 2009. Tabakmonitoring - Schweizerische Umfrage zum Tabakkonsum (2009, September). Retrieved Jan. 29, 2010 from http://www.bag.admin.ch/themen/drogen/00041/07322/index.html?lang=de

${ }^{15}$ Marco Boneschi, Alessia Antonietti, Angelo Tomada, Peter J. Schulz and Simone Ehmig, Rapporto: ICH progetto ESAGONO. Research report. Università della Svizzera italiana, Institute of Communication and Health, Center for Applied Research in Communication and Health (ARCHE), April 2008. 
Table 1: Overview of argumentative fields in the coverage of smoking bans in 17 Swiss newspapers

\begin{tabular}{|c|c|c|c|c|c|}
\hline $\begin{array}{l}1 \\
\text { Argumentative field }\end{array}$ & $\begin{array}{c}2 \\
\text { Number of } \\
\text { arguments }\end{array}$ & $\begin{array}{c}3 \\
\text { Share of } \\
\text { arguments } \\
\%\end{array}$ & $\begin{array}{c}4 \\
\text { Share of arguments } \\
\text { advocating a } \\
\text { standpoint for the } \\
\text { ban within the } \\
\text { field, all papers } \\
\%\end{array}$ & $\begin{array}{c}5 \\
\text { Range }^{a}\end{array}$ & $\begin{array}{c}6 \\
\text { Standard } \\
\text { deviation }^{\text {a }}\end{array}$ \\
\hline Health & 3936 & 33 & 78 & $63-96$ & 7.6 \\
\hline $\begin{array}{l}\text { Legal protection and } \\
\text { freedom }\end{array}$ & 2273 & 19 & 55 & $23-65$ & 11.2 \\
\hline $\begin{array}{l}\text { Social relations/ } \\
\text { majority rules }\end{array}$ & 1766 & 15 & 81 & $60-94^{b}$ & $7.3^{\mathrm{e}}$ \\
\hline Economy & 1440 & 12 & 52 & $30-87^{c}$ & $14.1^{\mathrm{e}}$ \\
\hline Experience/compliance & 1098 & 9 & 89 & $69-100$ & $8.6^{\mathrm{e}}$ \\
\hline $\begin{array}{l}\text { Level of/time for } \\
\text { regulation }\end{array}$ & 572 & 5 & 72 & $37-100^{d}$ & $23.2^{\mathrm{e}}$ \\
\hline Other & 957 & 8 & & & \\
\hline Sum & 12042 & 101 & & & \\
\hline
\end{tabular}

${ }^{\text {a }}$ Refers to the distribution of the percentage in Column 4 over 17 newspapers.

${ }^{\mathrm{b}} 60 \%$ is based on just $\mathrm{n}=5$ statements in Sonntagsblick; next lowest percentage is $71 \%$.

${ }^{c}$ Excepting $100 \%$ based on just one argument in Sonntagsblick.

${ }^{d}$ Excepting Le temps with $\mathrm{n}=3$ statements and a share of $33.3 \%$

excepting Sonntagsblick due to low number of statements 
Table 2: Overview of correlations of editorial stance (independent variable) with various dependent variables

\begin{tabular}{|c|c|c|c|c|c|}
\hline $\mathrm{H}$ & Dependent variable & $\begin{array}{l}\text { Exp. } \\
\text { corr. }\end{array}$ & $\begin{array}{l}\text { Kendall's } \\
\text { tau_b }\end{array}$ & $\mathrm{p}$ & Result \\
\hline \multicolumn{6}{|c|}{ Synchronization } \\
\hline H1 & $\begin{array}{l}\text { Final standpoint of opinions and arguments in } \\
\text { news sections }\end{array}$ & + & $.35^{*}$ & .02 & Confirmed \\
\hline \multicolumn{6}{|c|}{ Weighting patterns } \\
\hline $\mathrm{H} 2$ & $\begin{array}{l}\text { Weight of arguments with an original standpoint } \\
\text { for the ban news sections }\end{array}$ & + & -.04 & .40 & Rejected \\
\hline H3 & Weight of argumentative fields in news sections & & & & \\
\hline a & Health & + & $.33^{*}$ & .03 & Confirmed \\
\hline b & Social relations / majority rules & + & $-.25\left(^{+}\right)$ & .08 & Rejected \\
\hline c & Experience / compliance & + & $-.28\left(^{+}\right)$ & .06 & Rejected \\
\hline d & Economic & - & .23 & .10 & Rejected \\
\hline e & Legal & - & $-.37^{*}$ & .02 & Confirmed \\
\hline \multicolumn{6}{|c|}{ Evaluation } \\
\hline H4 & Frequency of contradiction of ... & & & & \\
\hline a & ...arguments with original standpoint for ban & - & .16 & .18 & Rejected \\
\hline b & ...arguments with original standpoint against ban & + & $.52 * *$ & .002 & Confirmed \\
\hline \multicolumn{6}{|c|}{$\mathrm{H}=$ Hypothesis. } \\
\hline \multicolumn{6}{|c|}{$\begin{array}{l}\text { Exp. corr. = Direction of expected (hypothesized) correlation. } \\
{ }^{+} \mathrm{p}<.10 ;{ }^{*} \mathrm{p}<.05 ; * * \mathrm{p}<.01 ; \text { all significance tests are one-tailed. (Brackets indicate significance level } \\
\text { of correlations in the unexpected direction.) } \\
\mathrm{N}=17 \text { for all analyses }\end{array}$} \\
\hline
\end{tabular}


Table 3: Correlations between editorial stance and various independent variables within argumentative fields

\begin{tabular}{|c|c|c|c|c|c|c|}
\hline & \multicolumn{6}{|c|}{ Dependent variables } \\
\hline & \multicolumn{2}{|c|}{$\begin{array}{l}\text { Weighting of } \\
\text { original } \\
\text { standpoints }\end{array}$} & \multicolumn{2}{|c|}{$\begin{array}{c}\text { Frequency of } \\
\text { contradicting } \\
\text { standpoints for the } \\
\text { ban }^{b}\end{array}$} & \multicolumn{2}{|c|}{$\begin{array}{c}\text { Frequency of } \\
\text { contradicting } \\
\text { standpoints against } \\
\text { the ban }{ }^{c}\end{array}$} \\
\hline & tau & $\mathrm{N}$ & tau & $\mathrm{N}$ & tau & $\mathrm{N}$ \\
\hline Health & -.03 & 16 & .24 & 16 & -.03 & 14 \\
\hline Legal protection and freedom & $-.58 * *$ & 15 & $-.35^{*}$ & 14 & .21 & 16 \\
\hline Social relations/ majority rules & .12 & 15 & $-.41 *$ & 15 & .00 & 10 \\
\hline Economy & .12 & 16 & .17 & 14 & $.36^{*}$ & 15 \\
\hline Experience/compliance & -.23 & 15 & $-.28^{+}$ & 16 & .07 & 6 \\
\hline$A l^{\mathrm{a}}$ & -.04 & 17 & .16 & 17 & $.52^{* *}$ & 17 \\
\hline
\end{tabular}

${ }^{a}$ Also includes arguments in the field of level of/time for decision, and other arguments. Coefficients also shown in Table 2.

${ }^{b}$ Negative correlations expected.

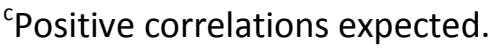

${ }^{+} \mathrm{p}<.10 ;{ }^{*} \mathrm{p}<.05 ;{ }^{* *} \mathrm{p}<.01 ;$ all significance tests are one-tailed.

Note: Varying $\mathrm{N}$ because papers with 5 or fewer arguments within a field and valence category were excluded from the analysis. 
Figure 1: Synchronization of editorial stance and stance in news stories

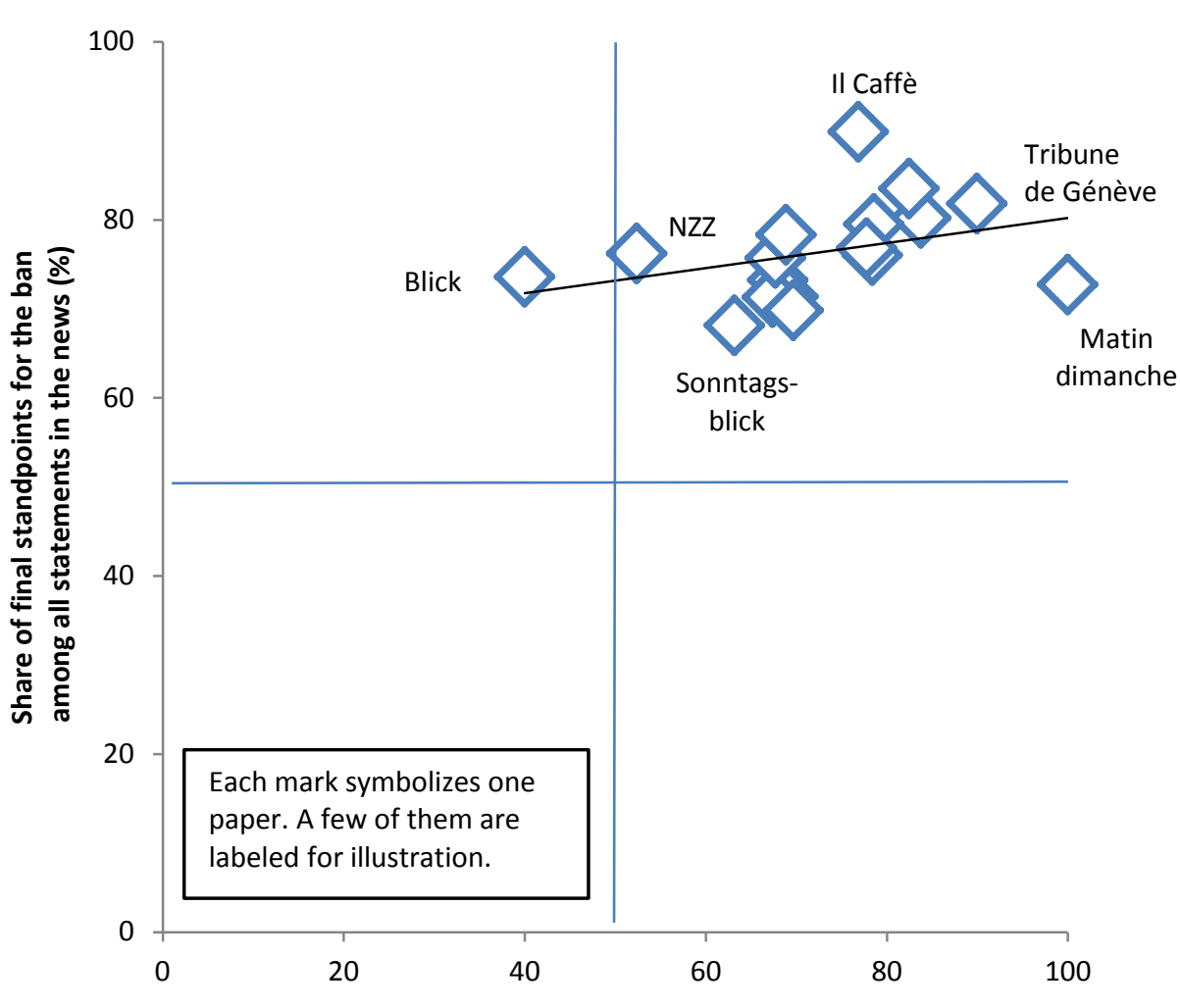

Editorial stance: Share of final standpoints for the ban among all statements in opinion pieces (\%) 
Figure 2: Correlation between editorial stance and weighting of health arguments in news stories

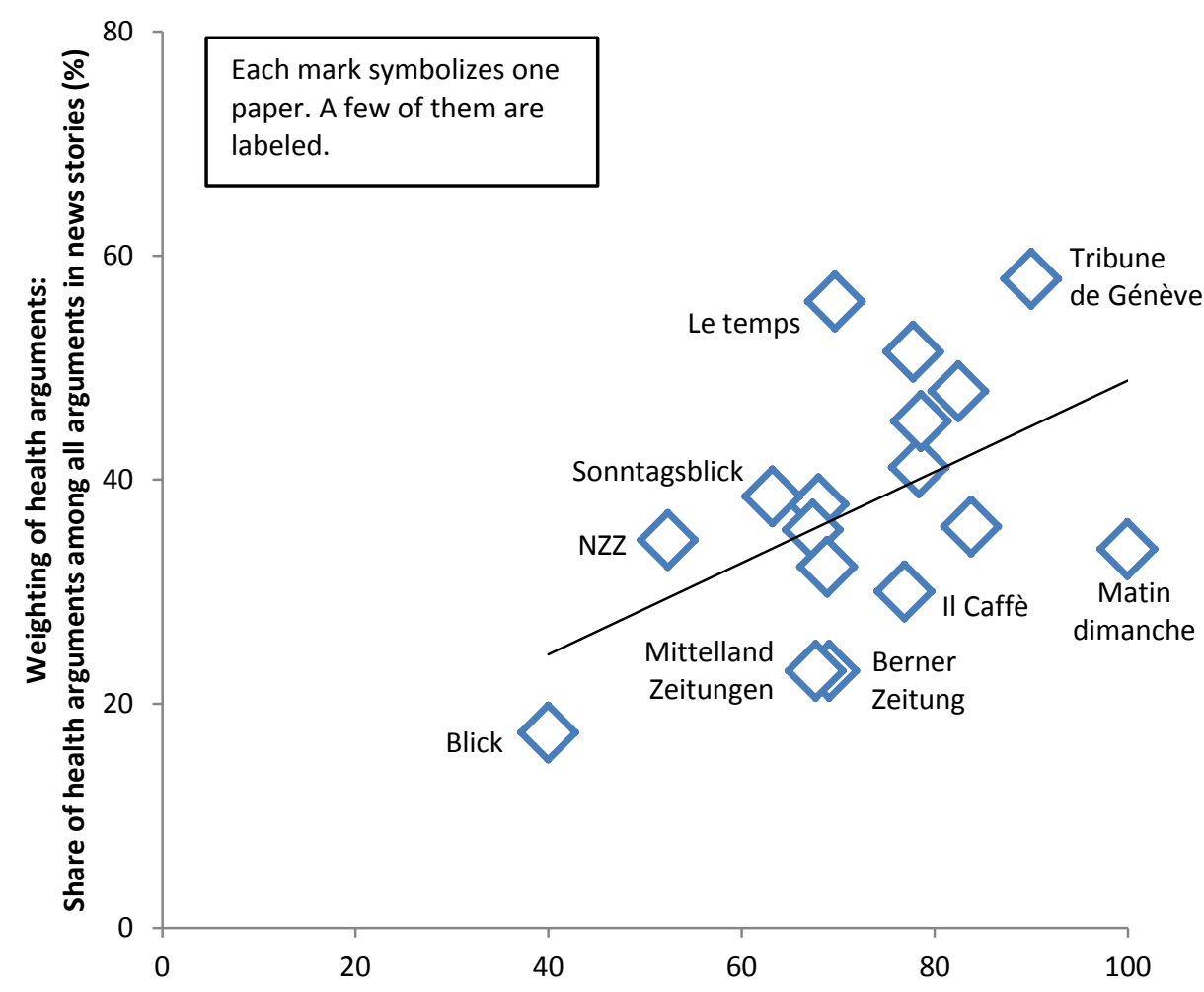

Editorial stance: Share of final standpoints for the ban among all statements in opinion pieces (\%) 
Figure 3: Correlation between editorial stance and weighting of legal protection/freedom arguments in news stories

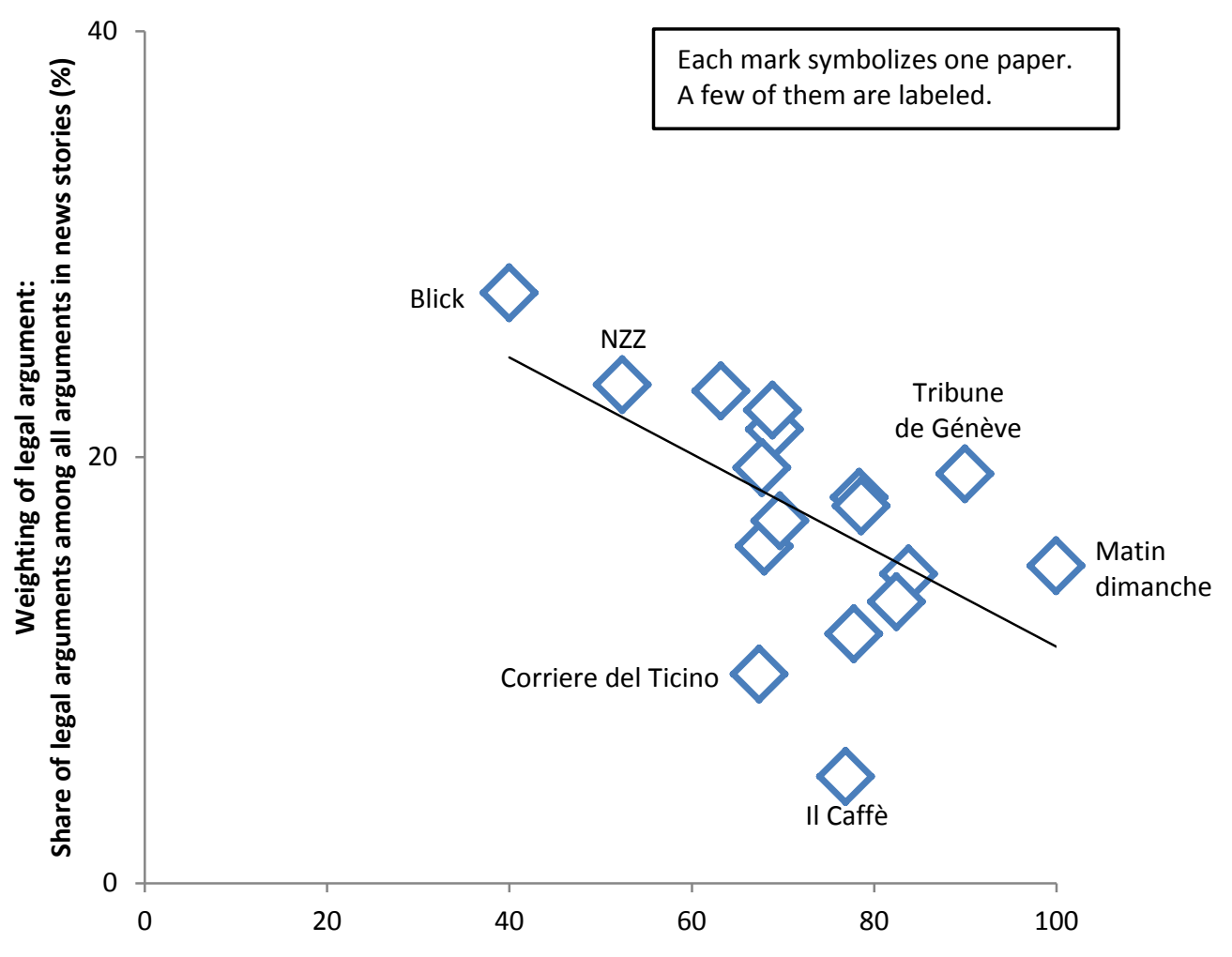

Editorial stance: Share of final standpoints for the ban among all statements in opinion pieces (\%) 
Figure 4: Correlation between editorial stance and likelihood of contradiction to original standpoints against the ban

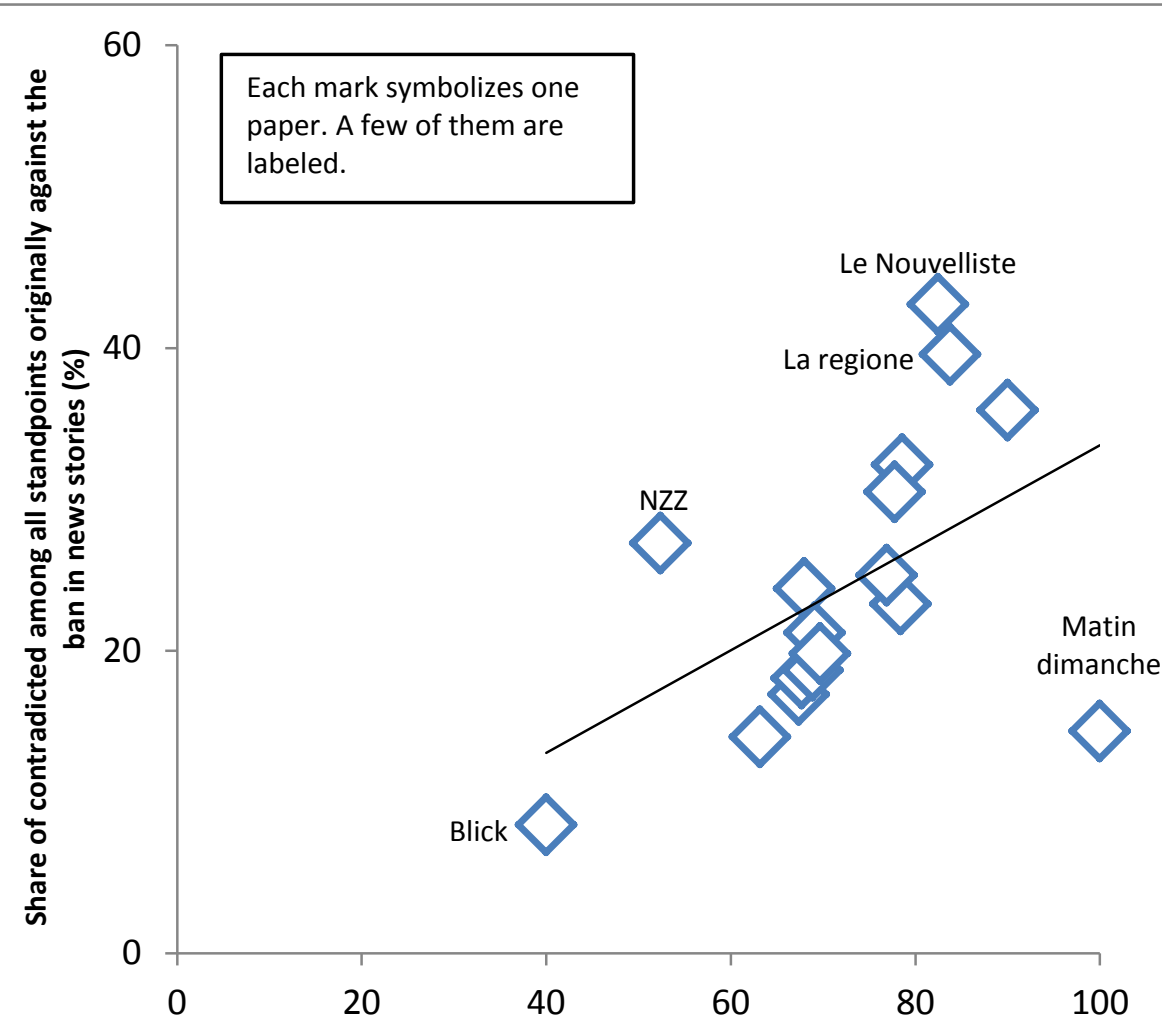

Editorial stance: Share of final standpoints for the ban among all statements in opinion pieces (\%) 